\title{
Necesidad, libertad y felicidad en la ética de Spinoza
}

\section{Necessity, freedom and happiness in the ethics of Spinoza Necessidade, liberdade e felicidade na ética de Spinoza}

Ana María Ayala Román'

Recibido: 24/06/2015 - Aceptado: 8/09/2015

\begin{abstract}
Resumen
En el presente artículo se analizará el modo cómo Baruch Spinoza recoge, en el seno de su filosofía, dos aspectos de la realidad que parecen ser contrarios: la necesidad y la libertad, proponiendo una salida a los problemas que se adscriben a la acción ética. Para esto es necesario mostrar cómo se presenta la necesidad en la filosofía de Spinoza, aclarar qué es libertad en su filosofía y analizar cómo se relacionan la necesidad y la libertad en el pensar y obrar, sobre todo aquellas que van encaminadas a conseguir la felicidad.
\end{abstract}

Palabras clave: Spinoza - Libertad - Necesidad - Felicidad - afecto.

\begin{abstract}
This article discusses how Baruch Spinoza brings together, within philosophy, two aspects of reality that seem to be opposite: necessity and freedom, and proposes a solution to the problems ascribed to the ethic action. For this, it is necessary to show how the philosophy of Spinoza addresses necessity and freedom and analyze how these two aspects relate in thought and action, especially in the way to achieve happiness.
\end{abstract}

Keywords: Spinoza - freedom - necessity - happiness - affection.

1 Colombiana. Candidata a Doctora en Filosofía, Universidad Católica de Valparaíso (Chile). Licenciada y Magíster en Filosofía, Universidad del Valle (Cali-Colombia). Becaria CONICYT-PCHA/Doctorado Nacional/2014-63140076. Contacto: anamariaayalar@gmail.com 


\section{Resumo}

No presente artigo vai se analisar o modo como Baruch Spinoza recolhe no seio da filosofia, dois aspectos da realidade que parecem ser opostos: a necessidade e a liberdade, propondo uma solução para os problemas que são atribuídos à ação ética. Para isto, é necessário mostrar como se apresenta a necessidade na filosofia de Spinoza, esclarecer o que é a liberdade em sua filosofia e analisar como se relacionam a necessidade e a liberdade no pensar e no obrar, sobre todo aqueles que vão encaminhados na consecução da felicidade.

Palavras-chave: Spinoza-liberdade-necessidade-felicidade-afeto.

Baruch Spinoza ha sido reconocido por la tradición filosófica como un determinista, esto quiere decir, que en su sistema filosófico afirma que todo está determinado por causas naturales y todo acontecimiento se puede explicar teniendo en cuenta dichas causas. Esto se puede entrever en afirmaciones que Spinoza hace de una forma categórica:

[...] nada sucede en la naturaleza que pueda ser atribuido a un vicio suyo [del hombre]. Porque la naturaleza es siempre la misma, y una y la misma en todas partes es su virtud y potencia de actuar; es decir, que las leyes y reglas de la naturaleza según las cuales se hacen todas las cosas y se cambian de unas formas a otras, son en todo tiempo las mismas; $y$ por tanto, una y la misma debe ser también la razón de entender la naturaleza de las cosas, cualesquiera que sean, a saber, por medio de las leyes y reglas universales de la naturaleza. Así, pues los afectos de odio, ira, envidia, etc., considerados en sí mismos, se siguen de la misma necesidad y virtud de la naturaleza que las demás cosas singulares; y admiten por tanto, ciertas causas por las que son entendidos y tienen ciertas propiedades tan dignas de nuestro conocimiento como las propiedades de cualquier otra cosa [...] (E III Prólogo) ${ }^{2}$.

2 Para las obras de Spinoza se utilizarán las siguientes abreviaciones: Ética (E). Tratado de la Reforma del Entendimiento (TRE). Tratado Breve (TB). Tratado Teológico Político (TTP). En el caso de la Ética, las referencias a las partes se harán de la siguiente forma: $\mathrm{E}$, parte (en número romano), proposición (P y números arábigos) o prólogo, 
Lo anterior muestra la tesis que esbozó Jonathan Bennett (1990) al declarar que Spinoza era un "racionalista explicativo", queriendo decir con esto que "Spinoza supuso que cualquier cosa que fuese podía explicarse, que si $\mathrm{P}$, entonces hay una razón por la que P" (34). Además de este "racionalismo explicativo" existe en Spinoza un "racionalismo causal"; afirma Bennett que una característica de este racionalismo es que la relación entre causa y efecto es determinada como necesaria. Es decir, en el "racionalismo causal" de Spinoza no hay distinción entre necesidad causal y lógica. "[Spinoza] cree que una causa se relaciona con su efecto como una premisa lo hace con una conclusión" (Id.35). Ahora bien, el "racionalismo explicativo" cae en un "racionalismo causal", puesto que frente a la explicación de un hecho $Y$ se dará la relación necesaria con su causa $X$, es decir, la explicación de $Y$ pasa necesariamente por la existencia de $X$ y la relación necesaria que se establece entre $\mathrm{X}$ y $\mathrm{Y}$.

Según la lectura de Bennett, Spinoza es un determinista, sin embargo, Spinoza no olvida y le da importancia al estudio ético, no sólo por su ánimo de explicar los afectos sino porque cree encontrar algo más en ese estudio: la libertad, algo que un determinista sin más, desdeñaría (como si estuviera afirmando que si no hay libertad, no hay ética). Como lo muestra la anterior cita de la Ética, el estudio sobre los afectos es de suma importancia en la filosofía espinocista; no es gratuito que algunos estudiosos de la filosofía de Spinoza, como Deleuze, afirmen que es una filosofía práctica. El mismo Spinocista al inicio de su Tratado de la Reforma del Entendimiento traza el horizonte del mismo y de su filosofía: la búsqueda de la felicidad.

Después de que la experiencia me enseñó que todas las cosas que ocurren frecuentemente en la vida ordinaria son vanas y fútiles; cuando vi que todas las cosas de las que recelaba y las que temía no contenían en sí nada de bueno ni de malo [...] tomé al fin la decisión de investigar si existía 
algo que fuese un bien verdadero, capaz de comunicarse [...] más aún: si existía algo con cuyo descubrimiento y adquisición yo gozara eternamente de continua y suprema alegría (TRE § 1).

Esta felicidad sólo se logra cuando se llega a un estado tal de libertad que hace que los individuos salgan de la servidumbre y puedan gobernarse según su conatus. Tal propuesta se aleja de los principales argumentos deterministas donde obviamente no existe la libertad humana, pues al estar todo determinado no hay cabida para acciones libres.

Pero, ¿no es contradictorio que en la filosofía de Spinoza coexistan estas dos posturas? En el presente escrito se intentará vislumbrar cómo en la filosofía spinocista se relacionan estas dos posturas sin llegar a una contradicción. Para esto es necesario mostrar cómo se presenta la necesidad en la filosofía de Spinoza, aclarar qué es libertad en su filosofía y analizar cómo se relaciona la necesidad y la libertad en el pensar y actuar.

\section{Dios como fundamento de la necesidad en el sistema spinocista.}

Al querer establecer un orden determinado en el mundo, es necesario empezar desde el ente perfectísimo, por el que los entes finitos existen. Este ente perfectísimo es Dios, por tanto todas las cosas dependen de Dios. Ahora bien, la concepción spinocista de Dios tiene características peculiares que la alejan de la tradición judeo-cristiana que había dominado el pensamiento occidental hasta el siglo XVII.

La tradición contra la que se alza la filosofía de Spinoza establecía, al igual que en Spinoza, una definición de Dios, una relación y acción de él en el mundo. A Dios se le considera como una entidad perfectísima, poseedora de unos atributos: omnisciencia, omnipotencia, suprema bondad y voluntad sin límites. Ahora bien, para los pensadores judeocristianos todo lo que existe es dependiente de Dios, pues suponen que las cosas existen por el acto creador de Dios, acto que responde a su voluntad y fines. La característica de esta voluntad y fines es la de 
ser incomprensibles para el hombre, lo único que puede captarse es cómo benefician al hombre las cosas creadas por Dios, apareciendo de esta forma el supuesto de que Dios ha creado las cosas para el beneficio del hombre.

Spinoza es un detractor de estas ideas, piensa que están basadas en imágenes que tienen los hombres de un dios personal, castigador o benefactor y no en una idea adecuada. Además, muchas de estas ideas hacen que el hombre tome a Dios como asilo de su ignorancia, pues al no poder determinar las causas de sus acciones y de los hechos externos, se refugia en los designios incomprendidos de Dios. Es esta idea de Dios la causante de que se establezca una dualidad en el mundo: alma/cuerpo, mundo/Dios, voluntad/entendimiento, razón/pasión, necesario/contingente. Así lo muestra Pollock, citado por Roth:

He [Spinoza] did not simply break off from theological speculation, and seek to establish philosophy on an independent footing; he seems intent on showing that theological speculation itself, when reason is once allowed free play, must at last purge itself of anthropomorphism and come round to the scientific view. Spinoza does not ignore theology, but provides an euthanasia for it (1963 51).

En la Ética Spinoza inicia definiendo "causa de sí" para después definir "Dios"; esto es significativo, pues para Spinoza lo importante en una definición, más que mostrar las propiedades del definiendum, es mostrar su causa (esencia o causa próxima). Esta clase de definición, denominada genética, se apoya en el análisis de los modos de conocimiento que realiza Spinoza en el Tratado de la Reforma del Entendimiento. En este análisis expone cuatro modos de conocimiento, pero lo que nos interesan aquí son los dos últimos. El tercer modo de conocimiento se da cuando se conoce o se define la cosa a partir de otra, es decir cuando se conoce algo a partir de los efectos (de sus propiedades). El cuarto modo de conocimiento se da cuando se conoce o define una cosa por su sola esencia o por su causa próxima (cf. TRE §19). La definición tal como es planteada por Spinoza depende del cuarto modo de conocimiento. El entendimiento debe conocer las cosas 
por sus causas y no por imágenes o sus efectos. La definición tradicional de Dios, según Spinoza, se basa en imágenes, ideas confusas y mutiladas de Dios. Los hombres conciben la idea de Dios desde sus supersticiones, desde la relación que tiene el cuerpo con las "cosas creadas por Dios", desde su creencia en la finalidad (Dios ha creado todo con la finalidad de hacer feliz al hombre). Es ésta la preocupación de Spinoza en la primera parte del Tratado Teológico-político, en la que se pretende mostrar cómo algunos teólogos y filósofos quieren poner a Las Escrituras como continuidad de sus pasiones, poder político y razonamientos erróneos:

Que les ocurra [a los hombres], en efecto, mientras son presa del recelo, algo que recuerde males o bienes ya pasados, y sobre ello augurarán si ha de serles el porvenir propicio o funesto; y engañados cien veces por los sucesos no dejarán de creer en los buenos como en los malos presagios. Son testigos de cualquier hecho extraordinario, que los llena de admiración y a sus ojos es un prodigio que anuncia la ira de los dioses, del ser supremo. Y no templar su cólera por plegarias y por sacrificios parece una impiedad a esos hombres que la superstición conduce y que no conocen qué es y qué significa la religión. Quieren hacer a la naturaleza entera cómplice de su delirio, y fecundos en ridículas ficciones, la interpretan de mil modos maravillosos. (TTP 38).

Para establecer las características de la necesidad spinocista debemos, entonces, examinar la definición de "Dios" y la relación que se establece con otros términos tales como: "atributo", "acción", "necesidad" y "conatus".

\subsection{El Dios spinocista}

El primer libro de la Ética está dedicado a esclarecer y construir (en 36 proposiciones) la idea o concepto de Dios. Vamos a utilizar la definición que resume Spinoza en el apéndice de esta parte: 
Con esto he explicado la naturaleza de Dios y sus propiedades, como que existe necesariamente, que es único, que es y actúa por la sola necesidad de su naturaleza, que es causa libre de todas las cosas y cómo lo es, que todas las cosas son en Dios y dependen de él de tal modo que sin él no pueden ser ni ser concebidas, y, en fin, que todas las cosas han sido predeterminadas por Dios, no sin duda por la libertad de la voluntad o por el absoluto beneplácito, sino por la naturaleza absoluta o la potencia infinita de Dios.

El Dios spinocista, al igual que el de la tradición judeo-cristiana, es causa de sí, esto expresar la necesidad de su existencia. Este argumento ontológico expresa que la existencia es parte del concepto de Dios, donde el concepto, al referirnos a la causa — por la definición genética-, expresa que Dios es una substancia autocausada, y de esta autocausación depende la necesidad de la existencia. A la pregunta: ¿por qué existe Dios? se contestará: se debe a su naturaleza, en este sentido se encuentra la segunda demostración que realiza Spinoza a la Proposición 11 de la Primera Parte de la Ética:

[...] A cada cosa hay que asignarle una causa o razón, tanto de por qué existe como de por qué no existe. Por ejemplo, si un triángulo existe, debe darse una razón o causa de por qué existe; [...] Ahora bien, esta razón o causa debe estar contenida o bien en la naturaleza de la cosa o bien fuera de ella.

Ahora bien, la definición de Substancia como aquello que no depende de otra cosa para existir (E I 7 d) deja no sólo resuelto el problema de la existencia de Dios, sino que a la vez resuelve el problema de la existencia de las cosas que dependen de Dios: los atributos. En un concepto donde se afirma la existencia necesaria de la entidad, se afirma la existencia, de una forma necesaria, de todo lo que se deduce de ella. De esta forma Spinoza demuestra que la imposibilidad de existir de Dios vendría siendo una imposibilidad lógica, puesto que es necesario que Dios exista por su definición. 
En la proposición 34 del primer libro de la Ética, la autocausación se identifica con el poder: "[...] la potencia de Dios [que es su esencia] con la que él mismo y todas las cosas existen y actúan, en su misma esencia". Los medievales atribuían a Dios además de voluntad y entendimiento el poder para hacer las cosas. El poder es para Spinoza el único atributo por el que Dios obra sobre sí mismo y sobre las demás cosas que dependen de él. El poder sería en este caso la esencia de Dios. Todo lo que está en el poder de Dios, que es infinito, necesariamente debe existir. La providencia, por la que Dios ordena y conserva las cosas, es para Spinoza lo mismo que el conato o poder con el que Dios se conserva ( $c f . K V \vee \S 1$ ). Spinoza considera, de esta forma, que no poder existir es impotencia, por lo que el ente absolutamente infinito debe existir (E I $114 d$ ).

Dios consta de infinitos atributos, los cuales expresan su ilimitación y perfección (puesto que Spinoza define a la "perfección" como "realidad"). Esta ilimitación expresa la pura afirmación de la naturaleza de Dios, puesto que si no poseyera infinitos atributos, y en este sentido fuera limitado, habría una negación en la naturaleza de Dios. De la proposición 8 de la Ética en adelante, la perfección de Dios, que se debe a su infinitud, se torna compleja, puesto que ya no sólo se debe a la necesidad de su existencia sino a la posesión de infinitos atributos. Debemos entender aquí por "poseer infinitos atributos" la proposición "poseer todos los atributos". Pero ¿cómo pasa de una sustancia simple, cuyo atributo es existir, a una compleja? Spinoza lo hace mediante el principio que afirma que a una mayor realidad le corresponde una mayor complejidad; esta mayor complejidad se expresa en la potencia que tiene Dios para existir así como en la potencia que tiene Dios para producir cosas ( cf.E I P11 y P17). Esta es la idea de expresión que se da en la ética: a un atributo le corresponde una esencia, esencia que se encuentra en otra cosa, que es única para todos los atributos. Así lo explica Deleuze:

[...] La esencia en cuanto esencia no existe fuera de los atributos que la constituyen. La esencia se distingue pues en los atributos donde existe. Existe siempre en un género, en tanto géneros como atributos hay. Cada atributo en con- 
secuencia es la existencia de una esencia eterna e infinita, de una esencia particular. Es en este sentido que Spinoza puede decir: existir propio a la esencia de los atributos, pero precisamente existir en los atributos. O incluso: «la existencia de los atributos no difiere de su esencia». La idea de expresión, en la Ética, recogerá ese primer momento: la esencia de la substancia no existe fuera de los atributos que la expresan, de manera que cada atributo expresa una cierta esencia eterna e infinita. (1975 36).

La unidad de la sustancia, Dios, se establece en el corolario de la proposición 14 ("Dios es único") y la proposición 15 ("aparte de Dios, no se da ni se puede concebir ninguna sustancia"). Esta unicidad depende de la indivisibilidad de Dios propuesta en las proposiciones 12 y 13 :

P12: "No se puede concebir con exactitud ningún atributo de la sustancia, del que se siga que la sustancia pueda ser dividida"

P13: "La sustancia absolutamente infinita es indivisible"

El requerimiento de que la sustancia debe ser indivisible, en este caso única, puede deberse a tres razones: 1) algo infinito no se puede conformar de algo finito (como se expone en el escolio de la proposición 13), 2) Spinoza piensa que las cosas compuestas por partes son vulnerables, y 3) si la sustancia se dividiera en partes, ésta podría ser un adjetivo de sus partes.

Pero ¿es la afirmación de la indivisibilidad de Dios, y por tanto de su unidad, sólo una forma de mostrar la perfección de Dios? No. La afirmación de la indivisibilidad y unidad de la sustancia tiene un efecto adicional y más importante en la ontología de Spinoza: afirmar la unidad de la naturaleza. Esta unidad se expresa en Dios en su existencia y su producción, en tanto que es en la autocausación donde Dios produce los infinitos atributos y, por tanto, los modos de éstos. Es importante resaltar en este punto que una de las mayores oposiciones tempranas que se dieron al pensamiento de Spinoza fue la de Samuel Clarke, quien argumentaba contra Spinoza que de la conjunción de un ser necesario, que actúa necesariamente, y el principio de 
razón suficiente no podría haber la diversidad que se encuentra en el universo (cf. Yenter 2014). Contra esta posición de Clarke se puede contraargumentar, como se ha resaltado antes, que la producción de Dios, atributos y modos, son infinitos, por tanto la naturaleza consta de diversas expresiones de Dios.

Ahora bien, se debe vincular otro concepto central de la filosofía spinocista: la causa inmanente. La relación de la inmanencia de Dios con su unidad se encuentra expresada en proposición 15 del libro primero: "Todo lo que es, es en Dios, y sin Dios nada puede ser ni ser concebido". Esta inmanencia no sólo postula la total unidad de la naturaleza, sino también el tipo de conocimiento que se tiene de esta naturaleza: el conocimiento por la causa o la esencia. De esta forma nada queda separado, a la hora de conocer, del conocimiento de Dios. La inteligibilidad del mundo queda garantizada por la unidad de Dios.

Aquí es importante comprender otra propiedad de Dios: ser causa libre. Parece que hasta este momento sería imposible hablar de causas libres, en un sistema donde sólo existe la necesidad, tanto de la existencia de Dios como de los atributos y modos de éstos, pues se caería en una contradicción. Es en la solución de esta aparente contradicción donde hallaremos el eje central de la filosofía spinocista: la relación entre libertad y necesidad.

La producción de Dios, que se debe a su potencia, es libre. Esta libertad es definida por Spinoza así: "Se llamará libre aquella cosa que existe por la sola necesidad de su naturaleza y se determina por sí sola a obrar" (E II def. 7). Esta definición de la libertad es una propiedad abstracta, puesto que no se aplica a ninguna entidad específica; no es hasta las proposiciones 16 y 17 donde se le da esta propiedad a Dios. La existencia de la propiedad de la libertad queda garantizada por la misma esencia de Dios, puesto que al estar identificada su esencia, existencia y producción todo lo real depende enteramente de él, de aquí que la necesidad y naturaleza de Dios no depende de nada externo. Ahora bien, es la potencia productiva, o conatus, lo que asegura que sea causa libre, pues la producción de Dios se debe a la sola necesidad de su naturaleza (P16) o a las solas leyes de su naturaleza (P17). 
Este concepto de libertad se aleja de la versión que operaba en la tradición: una libertad unida a la contingencia y al libre albedrío, que concebía a la facultad de la voluntad como la causa de que un acto fuera libre. La libertad spinocista no es indeterminada, la contingencia no tiene cabida en ella, es la afirmación absoluta de la necesidad. En el Escolio de la Proposición 17 de la primera parte de la Ética, Spinoza no sólo se contenta con demostrar y explicar en qué consiste la acción libre de Dios, sino que critica la concepción tradicional de libertad de esta forma:

a. Crítica a la postura que afirma que Dios no produce todo lo que está en potestad de producir.

Los pensadores judeo-cristianos trataban de poner de manifiesto la perfección de Dios por medio de la suposición de que la acción de Dios, por la que crea, es una acción libre, es decir, una acción que no es necesaria, sino voluntaria, que sólo depende de la decisión de Dios de crear o no crear tal o cual cosa. Esta posición se puede vislumbrar en Tomás de Aquino cuando afirma:

Algunos sostuvieron que Dios había obrado por necesidad de naturaleza al producir las cosas a la existencia. Si esto fuera verdadero, Dios no podría reducir algo a la nada, como no puede mudarse de naturaleza. [...] esta opinión es falsa y completamente contraria a la fe católica, que confiesa que Dios ha sacado todas las cosas a la existencia por libre voluntad [...] Así, pues, que Dios comunique el ser a las criaturas depende de la voluntad divina. E igualmente las conserva en su existencia, causando en ellas continuamente el ser. (2001 894).

Se supone, por tanto, que Dios es libre porque su voluntad puede decidir no crear lo que está en su potestad. Este pensamiento se encuentra unido a otro: sugerir que Dios produce cosas infinitas va en contra de la creencia en la omnipotencia divina. Dios al crear algo infinito agotaría su poder de crear; a la vez se dice que Dios no crea cosas perfectas porque él tiene el poder de crear otras más perfectas y así no concluiría su poder de crear. Frente a este razonamiento Spinoza 
concluye lo contrario: tales características de la causalidad de Dios no implican la perfección de Dios, sino, antes bien, su imperfección. Si Dios no puede producir algo perfecto e infinito, refleja su impotencia, no lo contrario; si Dios no puede crear lo que se encuentra en su potestad es imperfecto. Además de la naturaleza perfecta e infinita de Dios se siguen necesariamente los modos perfectos e infinitos ( $E$ I P33 2esc.).

2. Crítica a la postura que afirma que la producción de Dios se debe a su voluntad y entendimiento.

Spinoza niega que Dios sea un ser con entendimiento y voluntad. Una declaración a este respecto es que los hombres, por ignorancia de las primeras causas, le atribuyen a Dios cualidades que en realidad no le pertenecen, afectos humanos que nada tienen que ver con él. Además le atribuyen a Dios atributos que para los hombres son los más perfectos en ellos y, por tanto, deben estar en Dios en un más alto grado. Spinoza afirma, en la proposición 31, que el entendimiento, la voluntad, el deseo y el amor, no pertenecen a la naturaleza de Dios. El entendimiento y la voluntad, atributos tradicionalmente expresados de Dios, son sólo ciertos modos del pensar, por lo que han de ser entendidos por medio del atributo del pensamiento. Si los medievales identificaron la voluntad y el entendimiento con la esencia de Dios, Spinoza desvirtúa esta opinión convirtiéndolos en modos que por la definición V de la Primera Parte de la Ética se entienden como: "aquello que es en otra cosa, por medio de la cual es también concebido" (E I 3 def.). Por ende estos atributos no pueden aplicarse a la esencia de Dios, que al ser una substancia, es algo que se concibe por sí. Esta definición aleja a la voluntad y al entendimiento de la esencia de Dios, pues ésta se entiende por sí.

Si el anterior argumento pone de manifiesto que la voluntad y el entendimiento no pueden constituir la esencia de Dios, Spinoza utiliza otro argumento que cambia toda la visión que se sostenía sobre la voluntad. La acción voluntaria es una acción que va en contra de la necesidad, es decir, es la antítesis de la afirmación de que aquella acción dependa de una causa externa o que de la misma esencia de 
la cosa se sigue necesariamente algo. En la proposición 32, Spinoza llama a la voluntad "causa necesaria". Al ser la voluntad un modo, es determinada a existir y obrar de cierta manera (E P26); por esto la voluntad no puede ser llamada libre. Además las cosas determinadas por Dios, en este caso la voluntad, no pueden por sí mismas convertirse en indeterminadas (E P17).

\subsection{La contingencia}

Ya se ha mostrado cómo Spinoza ha construido, por medio de su concepto de Dios, una necesidad absoluta, donde todo lo real está determinado por la potencia de Dios. Sin embargo, Jonathan Bennett propone, de una manera poco contundente, una interpretación en la que Spinoza afirmaría "verdades contingentes", pues cuando trata de "Dios mirado desde abajo", es decir, desde las cosas finitas, a las que Bennet denomina "particulares", puede entreverse la afirmación de la contingencia (117 ss). Para establecer esta aseveración Bennett se apoya en la proposición 28 de la primera parte de la Ética. En esta proposición Spinoza dice que algo finito no puede provenir de algo eterno y absoluto (los atributos de Dios), pero es causado por algo igualmente finito, y éste a su vez es causado por otra cosa finita (y así hasta el infinito). Ahora bien, Bennett parece olvidar que Spinoza afirma, en esta misma proposición y en su escolio, que estos particulares son afecciones de un atributo de Dios, por lo que dependen de él, pero no como causa próxima en el orden de una cadena causal, sino siendo Dios la causa y esencia de todo:

Como algunas cosas debieron ser producidas inmediatamente por Dios [...] se sigue de aquí: $1 .^{\circ}$ ) que Dios es causa absolutamente próxima y no, como dicen, en su género, de las cosas inmediatamente producidas por él. Se sigue: $2{ }^{\circ}$ ) que Dios no puede decirse propiamente que es una causa remota de las cosas singulares, a no ser por el objeto de distinguir a éstas de aquellas que produjo inmediatamente o más bien que se siguen de la naturaleza absoluta de Dios. Pues por causa remota entendemos aquella que no está en 
modo alguno unida a su efecto. Ahora bien, todas las cosas que son, son en Dios y dependen de tal modo de Dios que sin él no pueden ni ser ni ser concebidas. (E I P28 esc.).

Otro problema que tiene la interpretación de Bennett es que parece olvidar la unidad que ha establecido Spinoza, una unidad no sólo de Dios, como ente indivisible, sino de Dios con la naturaleza, llegando a la identificación de Dios con ella. Esta unidad también se encuentra entre "el orden del ser" y el "orden del pensar" y es garantizada por el paralelismo. De esta forma, así como lo señala Deleuze, Spinoza, al igual que Avicena, resuelven la distancia que se presenta entre el ser necesario y las criaturas contingentes, pues el filósofo persa considera que aunque el mundo esté constituido de seres posibles (contigentes), éstos no dejan de ser necesarios. No es que lo posible se vuelva necesario por sí mismo, sino que lo hace porque la necesidad la recibe de un ser necesario: las cosas son posibles por sí, pero necesarias por otro (el Ser necesario). En esta perspectiva, Avicena no distingue esencia de existencia, puesto que cada esencia tiene la existencia "como debe de ser", es decir, como es necesario. (cf. Deleuze 1975 186).

Que las cosas se sigan necesariamente de la esencia divina establece la relación entre Dios y sus efectos. Dios y la naturaleza no han de pensarse separados. Es por esto que Spinoza asemeja a Dios con la naturaleza, entendiendo a ésta no como la suma de partes, sino como un todo infinito y eterno. Este pensamiento de Spinoza está en consonancia con la totalidad de su sistema filosófico. Dios es la única sustancia existente, fuera de él no existe nada, pues si se afirmara lo contrario, se estaría dando la posibilidad de la existencia de otra sustancia. Además, si existe algo que no sea Dios, él no sería infinito, lo que es una imperfección, puesto que se podría negar algo de Dios. Carl Gebhardt expresa en las siguientes palabras el sentido del "deus sive natura":

[...] Spinoza parte del concepto de la sustancia como aquello que existe en sí y es concebido por sí mismo; equipara a Dios, como esencia absoluta e infinita, con la sustancia. A 
la naturaleza de la sustancia pertenece tanto la existencia como la infinitud, porque todo ser finito sería negación parcial. En la igualdad "Dios o la naturaleza", naturaleza no significa, de ningún modo, el mundo visible, sino la total plenitud del ser. Cuanto más ser tiene una cosa, tantos más atributos o potenciales del ser le corresponden y por eso, para Spinoza, Dios es la sustancia que consiste en infinitos atributos, cada uno de los cuales expresa su esencia eterna e infinita. Si Spinoza transfiere así el mundo a la divinidad, entonces es claro que la divinidad es inmanente al mundo. Sustancia es para él, lo que existe en sí. Y por tanto, todo lo que ocurre, ocurre por las leyes de la naturaleza infinita de Dios. Dios es la causa inmanente de todas las cosas. Él es naturaleza naturante, el Uno; y naturaleza naturada, el Todo; es Uno y Todo. (1977 103).

Spinoza determina qué es "contingencia" en la Ética en la proposición 33. Lo más importante de su concepción es que afirma que la contingencia no es algo que realmente se dé en la naturaleza, puesto que en la naturaleza sólo podemos hablar de lo necesario o imposible, en relación con la esencia o la causa de algo. Una cosa es necesaria por su propia naturaleza cuando no necesita del concurso de algo externo para ser, por ejemplo, Dios es un ente necesario porque su esencia implica la existencia. A la vez, la existencia de un hecho en el mundo es necesaria porque se sigue del orden de causas y efectos que tienen como causa última la potencia de Dios (que es su esencia, luego es necesaria). Ahora, una cosa es imposible porque su naturaleza implica una contradicción manifiesta, por ejemplo, un círculo cuadrado (TRE §36). La imposibilidad, tal como la expresa Spinoza, estaría más en el orden de "imposible por su naturaleza" que "imposible por su causa", puesto que dada la causa debe darse el efecto: algo es imposible cuando hay una contradicción en su naturaleza, no porque haya una contradicción entre el efecto y la causa.

Pero ¿qué es entonces la "contingencia"? La contingencia es el modo con el que llamamos a algunas cosas de las que ignoramos si son necesarias o imposibles, esto porque desconocemos si su naturaleza 
implica contradicción o no, o desconocemos sus causas, por lo que no podemos decir con certeza que son necesarias o imposibles.

La razón por la que Bennett afirma que Spinoza podría haber afirmado "verdades contingentes" queda contraargumentada afirmando que lo finito está unido con lo infinito, y que si bien lo finito no es necesario por su naturaleza (E P24), sí es necesario por el orden de la serie causal.

\subsection{La necesidad en el pensar y actuar: una naturalización de la explicación de los asuntos éticos}

La unidad de la realidad garantiza su inteligibilidad, tal vez sea por esta razón que Spinoza no puede aceptar los principios voluntaristas de la filosofía cartesiana, donde sólo ve oscuridad: el ocultamiento de la verdad, verdad oscurecida por la suposición de una voluntad libre y caprichosa a la que no se puede comprender. La voluntad no es sólo el concepto sobre el que se fundamentó la ética, desde la Antigüedad hasta la Modernidad, sino que es el bastión de la ignorancia. La inteligibilidad del dios spinocista, aquel dios que sigue las leyes de su naturaleza, asegura la inteligibilidad del mundo. A este problema se refiere Jean Paul Margot en su libro La Modernidad: una Ontología de lo Incomprensible, cuando habla de la necesidad de la certeza para el hombre moderno; esta necesidad tiene una razón: la ininteligibilidad debida a una concepción determinada de Dios: un dios todopoderoso y voluntarioso:

Si la cuestión que se hace de sí mismo el hombre separado del mundo desde el cual se comprendía hasta el siglo XIII es, en tanto que pregunta acerca de la naturaleza, una cuestión que se dirige a la vez a su esencia -la de ser una res cogitans- y a lo que fundamenta su existir-Dios-, es porque la pregunta acerca de la esencia del hombre no podría contentarse con una respuesta que la identifica con un existir radicalmente contingente e inestable, puesto que es otorgado por un Dios omnipotente, por una voluntad arbitraria y no por una inteligencia ordenadora. En efecto, al derrumbarse el cosmos medieval del siglo XIII se derrumba la concepción del mundo desde el cual el hombre se comprende al concebir un mundo a partir de las 
ideas que pertenecen al entendimiento divino y le sirven de modelo. (Margot 2004 17).

La certeza que requiere Descartes para revisar sus creencias y llegar a una verdad indubitable es con la que parte Spinoza: la idea de Dios. Esta es una idea verdadera, evidente por sí misma, por esto mismo no podemos tener duda de ella. Spinoza hace depender al conocimiento de una idea verdadera que sirve como "modelo" para encontrar las demás ideas en el orden debido. Cabe señalar que esta idea verdadera no es sólo la idea de un objeto, sino que es la certeza de los conocimientos, pues a partir del conocimiento de ella es imposible que haya equivocación (E II P43 esc.). Si afirmamos, al igual que Spinoza, que el método es la idea de la idea, es decir, es la reflexión que nace en el mismo acto de conocer y que por este acto reflexivo sabemos que sabemos, entonces, se debe afirmar que el mejor método es aquel que parte de una idea verdadera. El método más perfecto (el que llega al conocimiento perfecto, es decir, verdadero) parte de la idea de un ser perfectísimo: Dios. ¿Por qué Dios? Él es la causa inmanente de todo lo existente, es el origen de toda la naturaleza y, por tanto, todas las ideas proceden de su idea. Al estar todas las cosas comunicadas con Dios (por ser él su causa) pueden ser conocidas partiendo de su idea.

El conocimiento de Dios permite tener un conocimiento total, no mutilado, que es la característica de las ideas verdaderas; efectivamente, el error para Spinoza no se da por una absoluta ignorancia, es decir, carecer por completo de conocimientos, sino por la privación de un conocimiento. El error no nace de una falta total de conocimiento de algún ente, el error nace de un conocimiento mutilado de ese ente. Spinoza ejemplifica lo anterior de esta manera:

[...] los hombres se equivocan al creerse libres, opinión que obedece al solo hecho de que son conscientes de sus acciones e ignorantes de las causas que las determinan. Y, por tanto, su idea de "libertad" se reduce al desconocimiento de las causas de sus acciones, pues todo eso que dicen de que las acciones humanas dependen de la voluntad son palabras, sin idea alguna que les corresponda. (E II P35 esc.) 
Este ejemplo arremete contra Descartes. En Los Principios de la Filosofía, Descartes habla de la relación de la libertad con la predestinación divina, dice que la libertad no es algo de lo que nosotros tengamos una idea o significado, la libertad es algo que se siente cuando la ejercemos. A la pregunta de si la libertad tiene consonancia con la creencia de la predestinación divina, Descartes es claro al expresar que la predestinación no refuta la libertad humana, pues el desconocimiento de los designios de Dios hace que el yo se sienta libre. Demos un ejemplo. Yo me siento libre cuando realizo una acción (elegir $X$ en vez de $Y$ ), al no saber si esto estaba preordenado (por no saber los designios de Dios) me siento libre. Es claro que, desde la perspectiva spinocista, la noción de libertad que tiene Descartes es errónea, viene de un desconocimiento de las causas que lo mueven a actuar.

El análisis ético realizado por Spinoza es depurado del concepto de Voluntad, puesto que esta facultad era concebida como aquella que alejaba a los hombres del buen camino, según la tradición judeocristiana, o era la que alejaba al hombre de la verdad (ésta es la posición de Descartes en la Cuarta Meditación). La voluntad "no deja" realizar un estudio claro, certero, sin valoraciones morales -como las de bueno y malo, entendidas éstas desde la tradición religiosa- $y$, si se quiere, científico de los afectos, pues ella introduce la contingencia, la ininteligibilidad y el pecado.

Si el análisis y la explicación de las acciones del pensamiento y el cuerpo eran explicadas antes por medio del concepto de voluntad, el análisis de Spinoza se centrará en el deseo. Spinoza afirmará que es el deseo la causa de las acciones. Así como lo afirma Inmaculada Hoyos Sánchez (2012), este modo de analizar la vida humana le permite a Spinoza combatir cualquier forma de mitificación trascendente. La posición de Spinoza se detallará en lo que sigue.

El hombre pertenece a la naturaleza naturada, depende de las leyes divinas o naturales que son lo mismo. Las acciones son para Spinoza la expresión de la necesidad que se encuentra en la naturaleza, para nada ha de considerarse estas acciones como ajenas al orden natural y necesario. Pero esta aserción plantea un problema: ¿cómo conciliar 
la necesidad absoluta con la acción libre, y lo que es lo mismo, con la libertad? Pareciera que la posición de Spinoza terminara en la mera afirmación de una necesidad de la que nada puede escapar, pero incluso así, Spinoza dirigió casi toda su atención filosófica a los temas éticos o de índole práctica; esto quiere decir que aunque exista una necesidad imperante, de todos modos se puede hablar de acciones ético-políticas. Este estudio pasa por un examen detallado de las afecciones, las pasiones. Ahora bien, estas pasiones son vistas como potencias, no como carencias (el estoicismo, a veces impugnado, en la filosofía de Spinoza parece ilegitimo) y su estudio es un estudio a partir del cuerpo, de las determinaciones del cuerpo, que sigue, como todo, las leyes de la naturaleza. Según Aurelia Armstrong (2013), es esta la relación que guarda la filosofía spinocista y nietzcheana, y que las aleja de las concepciones estoicas, pues las filosofías, tanto del filósofo holandés como la del alemán, intentan comprender la naturaleza del hombre, y entienden esta naturaleza como un poder dinámico de afectar y ser afectado.

¿Por qué un estudio desde el cuerpo y no desde el alma? Spinoza pretende realizar una reflexión distinta a todos los filósofos que habían hablado sobre las afecciones. La mayoría de los filósofos realizan un análisis de las pasiones centrado en la razón, en este sentido, las pasiones son vistas como enfermedades, como carencias, como errores. En el capítulo 16 del Tratado Teológico-Político, Spinoza deja en claro que el problema de la potencia o naturaleza humana no tiene que ver con la razón, sino con la potencia de Dios (un Dios sin entendimiento y sin voluntad) que es la determinación de cada cual, su determinación natural, su conatus:

No reconocemos aquí diferencia alguna entre los hombres y los demás seres de la naturaleza, ni entre los hombres dotados de razón, ni aquellos a quienes verdaderamente les falta, ni entre los fatuos, los locos o los sensatos. Aquel que produce una cosa según las leyes de su naturaleza, lo hace con pleno derecho, puesto que ha obrado según determinaba su naturaleza, y no podía obrar de otro modo.

Por esto entre los hombres cuando se les considera viviendo bajo el solo imperio de la naturaleza, aquel que no conoce la razón o que 
no posee el hábito de la virtud, y vive bajo las únicas leyes de su apetito, tiene tanto derecho como aquel que arregla su vida a las leyes de la razón [...] Así, pues el derecho natural de cada hombre no se determina por la sana razón, sino por el grado de su poder y de sus deseos [...] No es extraño, pues la naturaleza no se limita en el molde de la razón, que sólo atiende a la utilidad verdadera y a la conservación de los hombres, sino a otras infinitas que abrazan el orden de la naturaleza, en que el hombre es una partícula; por su sola necesidad se determinan todos los individuos, de cierto modo, a existir y a obrar. (TTP 276, 277).

Que "la naturaleza no se limita a la razón", es una crítica a los que piensan que la naturaleza se hizo a medida del hombre (aquellos que piensan que Dios hizo las cosas con la sola finalidad de beneficiar a los hombres). Que "el hombre es una partícula" está dirigido contra quienes piensan que el hombre es un "imperio dentro de otro imperio". El hombre, para Spinoza, al igual que cualquier ser de la naturaleza, no está determinado por su razón, sino por las leyes de su apetito, por su conatus. Ahora, Spinoza no está argumentando que el cuerpo sea superior al alma, su filosofía no sería tan revolucionaria si afirmara esto, lo que pretende Spinoza es superar el dualismo en el que se había envuelto la filosofía desde Platón. Este objetivo es superado al plantear que "el objeto de la idea que constituye el alma es el cuerpo, y existente en acto" (E II P13 dem.). En este sentido, se afirma un paralelismo entre cuerpo y alma que supera uno de los problemas centrales de la filosofía cartesiana: cómo se comunican alma y cuerpo (E II P7).

Por último, Spinoza advierte: "Nadie, en efecto, ha determinado por ahora qué puede un cuerpo, esto es, a nadie hasta ahora le ha enseñado la experiencia qué puede hacer el cuerpo por las solas leyes de la naturaleza [...] y qué no puede a menos que sea determinado por el alma" (E III P2 esc.). En este escolio Spinoza arremete contra los que piensan que el cuerpo es dominado por el alma, como un barco es controlado por su capitán; Spinoza pretende encontrar qué es lo que puede un cuerpo teniendo en cuenta las solas leyes de su naturaleza y, a su vez, llama la atención sobre la falta de claridad de 
estos filósofos, pues no han podido contestar la pregunta: ¿qué es lo que puede un cuerpo cuando el alma lo controla?

\subsection{Deseo y pasión: la causa de la acción ético-política}

El hombre por ser parte de la naturaleza tiene, como todas las demás cosas singulares, una potencia por la que se conserva en su ser. Esta potencia hace parte de la potencia de Dios o la naturaleza. Esta potencia de perseverar en el propio ser, o conatus, hace que el hombre se incline o apetezca lo que le es útil $y$, al contrario, rechace lo que le es perjudicial. Es este el sentido que le da Spinoza a lo bueno y a lo malo:

I. Por bien entenderé aquello que sabemos con certeza que no es útil.

II. Por mal, en cambio, lo que sabemos con certeza que nos impide poseer algún bien (E IV def. I-II).

Todo hombre, sea ignorante o sabio, persevera en su ser, esto es una ley natural, pues nadie persigue su autodestrucción. Este conatus es denominado por Spinoza como apetito o deseo y es: "la esencia misma del hombre en cuanto es concebida como determinada a hacer algo en virtud de una afección cualquiera que se da en ella" (E IV Definición de los afectos def. I). Si un hombre es afectado por un cuerpo exterior, este hombre tendrá conciencia tanto del cuerpo exterior como de su propio cuerpo y la modificación de su propio ser, es decir, del paso de una perfección mayor a una menor (sensación de tristeza) o de una perfección menor a una mayor (sensación de alegría). Esta conciencia de la modificación es la que marca la diferencia entre la pasión y el afecto (deseo con conciencia de sí mismo). El apetito o deseo hará que el hombre rechace o ame el objeto externo. La inclinación o rechazo hacia esto o aquello y la acción por perseverar en la existencia se rigen por este mismo deseo y potencia de existir.

No es la voluntad o el libre albedrío la causa de las acciones éticopolíticas. Según Harry Wolfson, Aristóteles había hecho la distinción entre voluntad y deseo: la voluntad afirma o niega los datos dados 
por la sensación y el entendimiento, mientras el deseo, gracias a estos datos, incita a perseguir o evitar una relación con algún objeto (cf. Wolfson 1962 Cap. XVII). Si bien se puede encontrar una relación entre el pensamiento de Spinoza y el de Aristóteles, se puede diferenciar, en la medida en que Spinoza niega la existencia de la voluntad como facultad; para él sólo existen afirmaciones y negaciones particulares que son las que conforman lo que se denomina intelecto.

La idea del deseo como causa de las acciones es complementada con las definiciones I y II de la Tercera Parte de la Ética; éstas son:

I. Llamo causa adecuada a aquella cuyo efecto puede ser percibido clara y distintamente por ella misma. Llamo, en cambio, inadecuada o parcial a aquella cuyo efecto no puede ser entendido por ella sola.

II. Digo que nosotros actuamos, cuando en nosotros o fuera de nosotros se produce algo de lo que somos causa adecuada, esto es, cuando de nuestra naturaleza se sigue algo, en nosotros o fuera de nosotros, que puede ser entendido clara y distintamente por ella sola. Y, al contrario, digo que padecemos, cuando en nosotros se produce algo o de nuestra naturaleza se sigue algo, de lo que no somos causa sino parcial.

Cuando un hombre sólo obra en virtud de su propia naturaleza es causa adecuada de ese obrar; la acción que viene del deseo, por ser éste esencia del hombre, puede ser entendida en virtud de él mismo. El conatus que lo define es el mismo que lo hace pertenecer a la infinitud. Ahora, por ser parte de la unidad, el hombre, necesariamente, tendrá contacto con otros seres singulares, $y$, en este sentido, la potencia del hombre es limitada, pues es limitada por la potencia de otros seres. Pero ser causa adecuada de sus acciones, no es un alejamiento del mundo, de la interacción con los otros seres singulares, que sería algo imposible por la unidad que impera, sino reafirmar su naturaleza buscando aquello que eleve su conatus y oponerse a todo aquello que lo disminuya.

Ahora Bien, la potencia de Dios no se expresa de la misma forma en todos los seres singulares, de ahí que cada cosa singular se esfuerce 
en cuanto puede, es decir, en cuanto a su potencia particular, en preservar su ser. La mayor potenciación del conatus dependerá de la no división de su ser. Esta "no división" del ser es entendida aquí como la no aniquilación de la potencia debido a causas externas. Es por esto que todo hombre busca lo que lo complemente, otros cuerpos afines al suyo, para conformar así una unidad.

En esta última parte es de importancia el alma, no porque ella conduzca el conatus, sino porque es ella la que se formará las ideas adecuadas para "decidir" los encuentros que el hombre necesita para elevar su potencia. En este sentido, el alma va a ser el medio por el cual el hombre discierne qué encuentros le son útiles y cuáles no. Es el conocimiento del alma lo que permite hacer una distinción entre el apetito como un "instinto ciego" y el deseo como "un afecto activo donde somos la causa". En esta perspectiva la ética, como lo señala Vicente Serrano, sería "una teoría del gobierno interior del sujeto y en el que el adecuado gobierno de los afectos determina que la máxima potencia se dé solo allí donde el sujeto se reconoce limitado en su propio poder" $(2014,43)$.

Pero esta idea spinocista no debemos entenderla como un intelectualismo al estilo de Sócrates y los estoicos. Spinoza es claro en enfatizar que: "Un afecto no puede ser reprimido ni suprimido sino por un afecto contrario y más fuerte que el afecto a reprimir" (E IV P7). En este sentido, el entendimiento debe transformarse en una fuerza que sustituya a la pasión que disminuye el cuerpo. El alma debe hacerse una idea adecuada de la afección (E V P3) y sólo puede hacer esto si conoce su cuerpo, pues el afecto es la idea de una afección del cuerpo. En consonancia con esta idea, aunque en análisis de la libertad de expresión, Alexander Carnera (2012) expone que dicha libertad tiene relación con la idea adecuada, idea que muestra cómo el hablar (el expresarse) es libre en sí mismo, no lo es porque se oponga a la autoridad, sino que es libre ahí donde se manifiestan relaciones inmanentes de afectos (que Carnera llama "assembled body") tanto con otros organismos como otros modos de hablar. 
Esta idea de Spinoza está unida al objetivo de la reforma del entendimiento que planteó Spinoza: al examinar los bienes que comúnmente tienen los hombres como los más altos (riqueza, honor, libido), el filósofo holandés busca encontrar algo que sea un bien verdadero que le dé una suprema alegría. Lo que encuentra Spinoza es que sólo enmendando el entendimiento puede alcanzar dicho bien. Ahora, ¿cómo se da el paso de un entendimiento pasivo a uno activo que pueda sustituir las afecciones que disminuyen el conatus del hombre? Ese paso se da cuando el conocimiento se convierte en amor a Dios (E V P15). Es por eso que dentro del lenguaje de las virtudes sólo encontramos el esfuerzo, el conatus que se expresa en el alma cuando conoce según la ciencia intuitiva. De esta forma, el aumento del conatus (alegría) conduce a la felicidad (entendida como beatitud). Según Frédéric Manzini (2014), la originalidad del pensamiento ético de Spinoza estribaría en lo anteriormente dicho, es decir, en mostrar la relación entre la aletitia y la beatitudo, pues el hecho que la aletitia permita conducir al hombre a la felicidad hace de ésta una "alegría activa".

\subsection{A modo de conclusión: el amor a Dios y las pasiones}

Aunque el conatus se encuentre en todos los hombres, esto no quiere decir que todos obren de forma libre, es decir, que sean causa adecuada de la acción. Este tema Spinoza lo desarrolla en la Cuarta Parte de la Ética. En ella se habla de la servidumbre humana, ésta es: "la impotencia humana de moderar y reprimir los afectos" (E IV Prefacio). Cuando el hombre es esclavo de causas externas, es decir, cuando sus actos no pueden ser comprendidos por la sola naturaleza de él mismo, se dice que es esclavo de la pasión, su vida es un puro padecimiento. Por ser parte de la naturaleza el hombre comparte con los demás seres una misma condición: es imposible que no se relacione con los demás entes de la naturaleza y su naturaleza no puede ser entendida sin las demás partes (E IV P2). En la medida en que se actúa por las leyes de la propia naturaleza, esa acción puede ser entendida por ésta y, en la medida en que el hombre hace esto, se hace dependiente de las propias leyes de su naturaleza y se hace libre. 
La experiencia de vida de Spinoza le hace reflexionar sobre algunos bienes que él consideraba buenos, pero que en últimas son "vanos y fútiles". Al darse cuenta de esto, Spinoza se propone encontrar algo que sea un bien verdadero. Este bien verdadero no ha de ser considerado como un algo trascendental, ya que el bien y el mal sólo se dicen en relación a algo. Aunque existe "lo bueno" y "lo malo", nada es bueno o malo en sí mismo, estos son juicios con los que el hombre se representa una buena o mala relación con un objeto. Es la propia naturaleza del sujeto la que lo hace aborrecer o amar algo: "ninguna cosa puede ser mala por lo que tiene de común con nuestra naturaleza; sino que, en la medida en que es mala para nosotros, también nos es contraria" (E IV P30). El bien verdadero es aquel bien que al actuar sobre el ánimo proporciona suprema alegría porque complementa la naturaleza de aquel que lo ha encontrado.

La consecución de tal fin supone un camino arduo e incierto y, a la vez, exige el abandono de bienes pasajeros que disipan el espíritu en la obtención del supremo bien alejándolo de éste, al distraer el alma "[...] que de ningún modo puede pensar en algún otro bien" (TRE $\S 3)$. Esto exige una nueva orientación de la vida.

El bien verdadero del que habla Spinoza son los medios para alcanzar una naturaleza superior, a diferencia del supremo bien que es el fin, es decir, gozar de aquella naturaleza, entendido este gozo como la unión del espíritu con la naturaleza eterna e infinita. El bien verdadero será entendido como el progreso epistémico que emprende un hombre al encaminar su conocimiento por la razón. Ahora bien, la nueva orientación de la vida supone un ejercicio filosófico que llevará al hombre a tener un verdadero conocimiento de las cosas, conocimiento que permite la unión del espíritu con la naturaleza. Es la verdadera filosofía el bien verdadero que sirve como puente para alcanzar la felicidad.

¿Qué supone la unión del espíritu con la naturaleza? Y, por tanto, ¿de qué cosas depende la felicidad del hombre? A medida que el hombre se hace consciente de la naturaleza y de sí mismo, él reconoce que pertenece a la totalidad, que se rige por las leyes necesarias de ésta; a la vez el hombre, al ser consciente de sí, reconoce las cosas que le son 
más útiles para su naturaleza, lo que hará que éste se relacione con entes que harán que se perfeccione su naturaleza. Por el contrario, si no tiene un conocimiento de su propia naturaleza, no sabrá lo que le es útil, padecerá pasiones, pues éstas nacen de opiniones, es decir, creencias sujetas a error por no reconocer las cosas que lo mueven a querer o no querer algo.

Pero la felicidad no depende sólo del conocimiento, sino del objeto del afecto que al poseerlo hace que el hombre consiga la felicidad. En el tratamiento que hace Spinoza de las pasiones afirma que la alegría y la tristeza dependen "de la cualidad del objeto al que nos adherimos con amor" ${ }^{\prime 3}$, esto es expresado por Spinoza de la siguiente forma: "[...] De hecho, nunca surgirán peleas por lo que no se ama; si desaparece, no habrá tristeza; ni envidia si es poseído por otro; ningún temor, ningún odio y, para decirlo en una palabra, ninguna conmoción de ánimo" (TRE §9). En este sentido, podemos entender la afirmación de Michel Henry de que toda "filosofía de la felicidad" es una "filosofía del ser"; así mismo se puede explicar que la filosofía de la felicidad de Spinoza empiece con una ontología donde se dé a Dios el sumo grado de independencia: el de sustancia, puesto que si no fuera de este modo la felicidad dependería de la subjetividad y no de la unidad o amor a Dios.

[...] Pero si la sustancia no es más que la obra de la conciencia constructiva, productora de verdad, si, como lo repite Kant, no hacemos más que encontrar en el objeto lo que ya introducimos en él, si el Ser no es más que nuestra representación, si no es más que nosotros mismos, ¿cómo adorarlo, cómo entregarnos a él? ¿Cómo admirar lo que no es más que nuestra obra? La felicidad absoluta, extática que soñó Spinoza supone la fusión con otro que nos arrebata. No podría existir en una concepción que, haciendo

3 Spinoza habla de la cualidad del objeto amado como sigue: "algunos objetos son perecederos en sí mismos; otros son imperecederos por su causa; pero hay un tercero que es eterno e imperecedero exclusivamente por su propia naturaleza". Spinoza, B., $T B$, cit, Segunda Parte, Capítulo V, $§ 2$. 
del objeto una simple producción de nuestra conciencia, del Otro un efecto y como una prolongación de nosotros mismos, suprime de hecho a ese otro. (Henry 2008 61).

Es la afección que causa el objeto amado lo que nos hace bien o mal. Tal afirmación va en contra de la idea universalista de Bien y Mal. Esta idea se encuentra en relación con la clasificación que hace Spinoza de las pasiones; según él, éstas son de dos clases: las alegres y las tristes. Las primeras consisten en el paso de una perfección menor a una mayor, mientras las segundas son el paso de una perfección mayor a una menor. El objeto de la pasión, por ser cambiante, no le permite al hombre gozar de una felicidad perfecta y eterna, sino de un placer o un dolor cambiante que puede terminar. Aun así, las pasiones alegres serán consideradas buenas por aumentar la potencia del ser, en cambio, las tristes serán denominadas malas por disminuir tal potencia.

La felicidad, a diferencia de la pasión, es un gozo continuo que, por tanto, depende de un objeto eterno y perfecto: este ser es Dios. Es éste el significado que le da Spinoza a la felicidad en el Tratado breve: "[...] nuestra felicidad, es decir, el amor de Dios, que hemos observado, es nuestra beatitud" (TB XIX §1). La felicidad es el amor a Dios, un amor que, a diferencia del amor cristiano a Dios, es el amor que le tiene el hombre a algo que conoce (contrario al amor por fe); Spinoza afirma que sólo se puede amar lo que se conoce. A diferencia del pensamiento medieval donde se debe tener fe y amar a Dios para conocerlo, en el pensamiento de Spinoza se debe conocer a Dios, este conocer devela lo que es Dios y hace que el hombre se una a él. Esta unión con Dios es el supremo bien, es decir, la conciencia de la unión del espíritu con la naturaleza. La unión con Dios es la participación con la totalidad y la eternidad, porque "todas las cosas están unidas mediante la naturaleza y unidas en una sola, a saber, en Dios" (Id. 5). Esta unión es consciente porque al conocerlo el hombre reconoce que Dios es lo mejor y más útil para potencializar su ser. 


\section{Bibliografía}

Armstrong, Aurelia. "The passions, power, and practical philosophy: Spinoza and Nietzsche contra the stoics", Journal of Nietzsche Studies 44 (March 2013): 6-24

Bennett, Jhonathan. Un estudio de la Ética de Spinoza, México: Fondo de Cultura Económica, 1990.

Carnera, Alexander. "Freedom of Speech as an Expressive Mode of Existence", International Journal for the Semiotics of Law 25 (2012): 57-69.

Deleuze, Gilles. Spinoza y el Problema de la Expresión, Barcelona: Muchnik Editores, 1975.

Descartes, René. Los Principios de la Filosofía, Madrid: Alianza Editorial, 1995. Meditaciones Acerca de la Filosofía Primera. Seguidas de las objeciones y respuestas. Bogotá: Universidad Nacional de Colombia, 2009.

Gebhardt, Carl. Spinoza, Buenos Aires: Editorial Losada, 1977.

Henry, Michel. La Felicidad de Spinoza, Buenos Aires: Ediciones La Cebra, 2008.

Hoyos Sánchez. Inmaculada, "La ontología naturalista de Spinoza como ontología de la pasión", Logos 45 (2012): 95-122.

Manzini, Frédéric. "La valeur de joie chez Spinoza", Etudes Philosophiques 109 (2014): 237-251.

Margot, Jean Paul. La Modernidad: una Ontología de lo Incomprensible, Cali: Universidad del Valle, 2004.

Roth, Leon. Spinoza, Descartes y Maimónides, New York: Russell \& Russell, 1963.

Serrano, Vicente. "El papel de los afectos en el pensamiento político de Spinoza", Ideas y Valores 63 (abril 2014): 31-57.

Spinoza, Baruch. Tratado Teológico-Político, Salamanca: Ediciones Sígueme, 1986.

Tecnos, 1989.

Tratado de la Reforma del Entendimiento, Madrid: Editorial

Tratado Breve, Madrid: Alianza Editorial, 1990.

Ética, Madrid: Editorial Trotta, 2009. 
Wolfson, Harry. The philosophy of Spinoza. Untolding the Latent Processes of His Reasoning. Vol. I y II, United States of America: Harvard University, America, 1962.

Yenter, Timothy. "Clarke against Spinoza on the manifest diversity of the world", British Journal for the History of Philosophy 22 (2014): 260-280. 